\section{REFERENCES}

Ayliffe, G. A. J., and Barber, M. (1963): Brit. med. J., ii, 202.

Ayliffe, G. A. J., and Barber, M. (1964): in the press.

Barber, M. (1961): J. clin. Path., 14, 385.

BARBER, M. (1964): J. gen. Microbiol., 34, 183.

Barber, M., Dutton, A. A. C., Beard, M. A., Elmes, P., and Williams, R. (1960): Brit. med. J., i. 11 .

BoroWSKI, J., KAMIENSKA, K., and RUTECKA, I. (1964): Brit. med. J., i, 983.

Cetin, E. T., and ANG, O. (1962): Brit. met. J., i, 52.

Chabbert, Y. A., and Baudens, J. G. (1962): Ann. Inst. Pasteur, 103, 222.
ERIKSEN, K., and ERICHSEN, I. (1963): Laeg., 125, 1234.

Harding, J. W. (1963): J. clin. Path., 16, 268.

JeVONS, P. M. (1961): Brit. med. J., 1, 124.

Jevons, P. M., Coe, A. W., and Parker, M. T. (1963): Lancet, i, 904.

Knox, R., and Smith, J. T. (1961): Lancet, ii, 520.

Richmond, M. J., Parker, M. T., Jevons, M. P., and JoHN, M. (1963): Lancet, i, 293.

Rolinson, G. N. (1960): Brit. med. J., i, 125.

StewarT, G. T., and Holt, R. J. (1963): Brit. med. J., i, 308.

Watanabe, T. (1963): Bact. Rev., 27, 87.

WilliaMS, R. E. O. (1959): Lancet, i, 190.

\title{
PREDICTING CLINICAL EFFECTIVENESS ON THE BASIS OF IN VITRO SENSITIVITY TESTS
}

\section{STEPHEN J. SEligman \\ University of California, Centre for the Health Sciences, Los Angeles.}

MANY variables affect the outcome of the encounter between bacteria and host. In recent years it has become quite fashionable to try to influence this interaction by means of various chemotherapeutic agents. With the advent of numerous semi-synthetic penicillins there is increasing need to make estimates or perhaps at least "best guesses" as to which of several compounds looks more promising for in vivo testing and to estimate under which situation one compound might be better than another. Such a guess is fraught with numerous chances for error but the desire to make it does give a convenient excuse for discussing some of the puzzling laboratory problems which affect the encounter between bacteria and antibiotic. Several groups of workers have called attention to the importance of variations in relative sensitivity of test organisms in comparing the activities of two antibiotics. Our attention was recently called to this fact when comparing ampicillin and penicillin $\mathrm{G}$ against both Esch. coli and Proteus mirabilis. Ampicillin generally had one-eighth the M.I.C. of penicillin $\mathrm{G}$ against Esch. coli but only half the M.I.C. against most strains of Proteus mirabilis. Another factor which affects the apparent "minimum inhibitory concentration" is the influence of serum binding as has been pointed out earlier in the conference. The factors which have caught our attention, however, have been of two varieties. One is the influence of mutants in the population of a given bacterial culture with increased resistance to the anti- biotic. The other is the influence of factors affecting the kinetics of bactericidal activity. The experiments to be reported here were performed with the acid salt ampicillin and a strain of Esch. coli originally isolated from a patient with asymptomatic bacteriuria.

Previous experiments had indicated that organisms which had regrown after exposure to relatively low concentrations of ampicillin were on occasion mutants with increased ability to inactivate ampicillin compared with the parent strain (Seligman and Hewitt, 1963). Such destruction was presumably due to a penicillinase but its nature has not yet been investigated.

More recently, by alteration in test procedure, it has become apparent that there is an entirely different class of mutants present which have increased inherent resistance of the individual organisms to ampicillin. These mutants were isolated by plating out various concentrations of an overnight culture onto plates containing increasing concentrations of ampicillin.

At a critical or threshold concentration, around $5 \mu \mathrm{g} . / \mathrm{ml}$. at $\mathrm{pH} \mathrm{7.3,} \mathrm{a} \mathrm{marked} \mathrm{fall} \mathrm{in}$ colony count occurred. Figure 1 shows the typical colonial morphology of a non-mucoid Esch. coli which was plated out at $10^{-6}$ dilution of an overnight culture. Figure 2 shows the varying colonial morphology of a $10^{-2}$ dilution of the same culture on plates which contained $6 \mu \mathrm{g}$. $/ \mathrm{ml}$. of ampicillin. Marked variation in colonial size is evident. The larger colonies have altered colonial morphology with depressed 


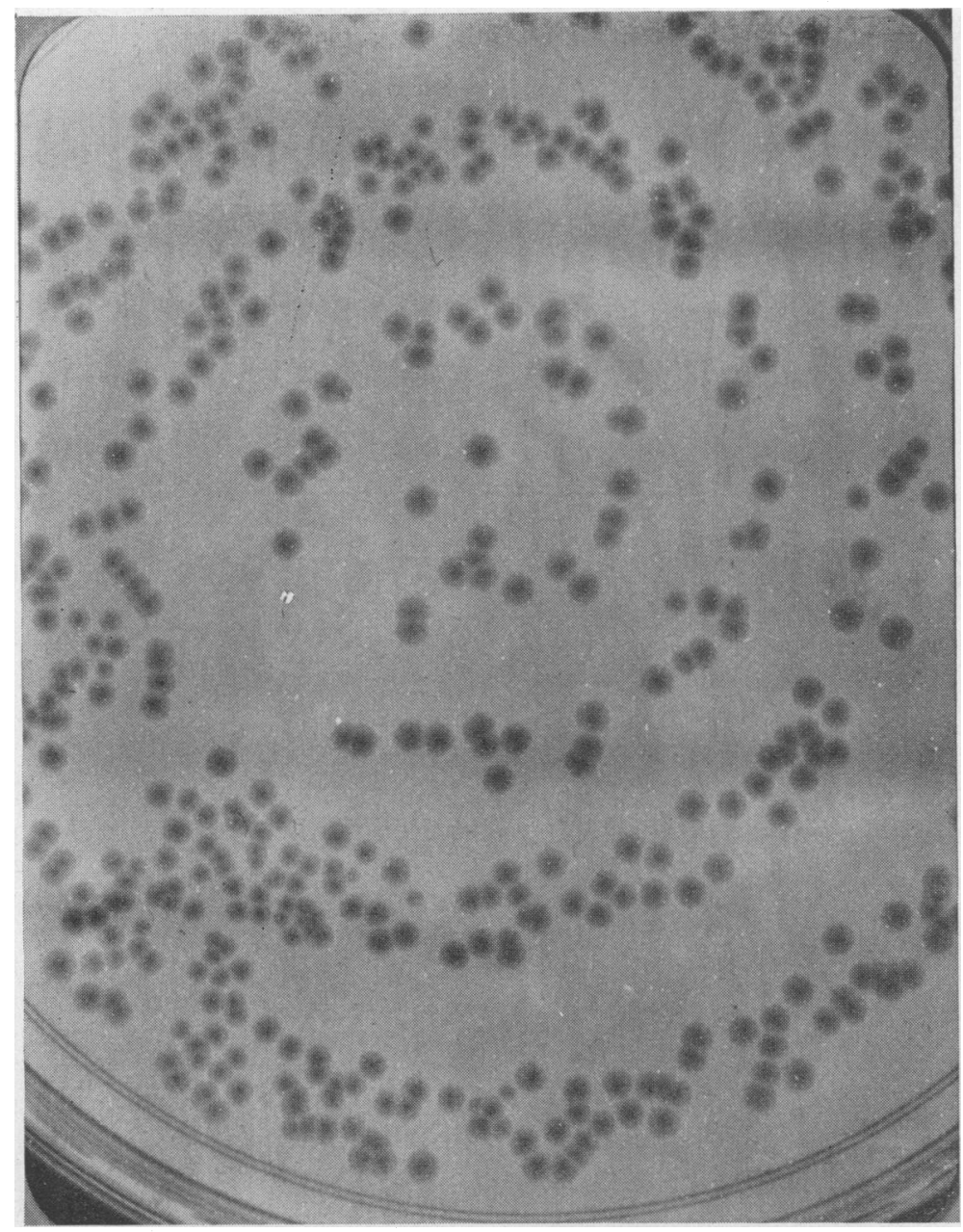

FIG. 1.-An overnight culture of Esch. coli diluted to $10^{-6}$ and plated on to trypticase soy agar.

and umbilicated centres. These large colonies invariably proved to be mutants with increased resistance to ampicillin and usually grew out with a similar colony count on plates without ampicillin and with $8 \mu \mathrm{g}$. ampicillin $/ \mathrm{ml}$. With repetition of this process, a series of stepwise mutants was isolated analogous to the staphylococcal mutants described by Demerec (1945) with increased inherent resistance to penicillin $\mathbf{G}$. In contrast to the staphylococcal mutants, however, the Esch. coli variants frequently had unaltered colonial morphology on antibiotic-free media and similar growth rates as their parent strain. These attributes raise the possibility that they may differ from their staphylococcal counterparts in having undiminished or only slightly diminished viru- lence. The extent to which they are important clinically is not known, but because of theirfrequency in the parent population it would?. appear possible that they tend to increase in numbers in the gastro-intestinal tract of individuals receiving penicillin. The increase ino resistance of the "first step" mutant was of relatively low magnitude and it might not be differentiated from its parent strain by tradi tional two-fold dilution sensitivity tests. Incidentally with the current ampicillin- $N$ Esch. coli system, growth in the last positive tube in the tube dilution sensitivity test was due to such mutants.

Exact enumeration of these mutants presento in the parent strain proved to be an exasperat $\stackrel{?}{?}$ ingly difficult task both on solid media and by 


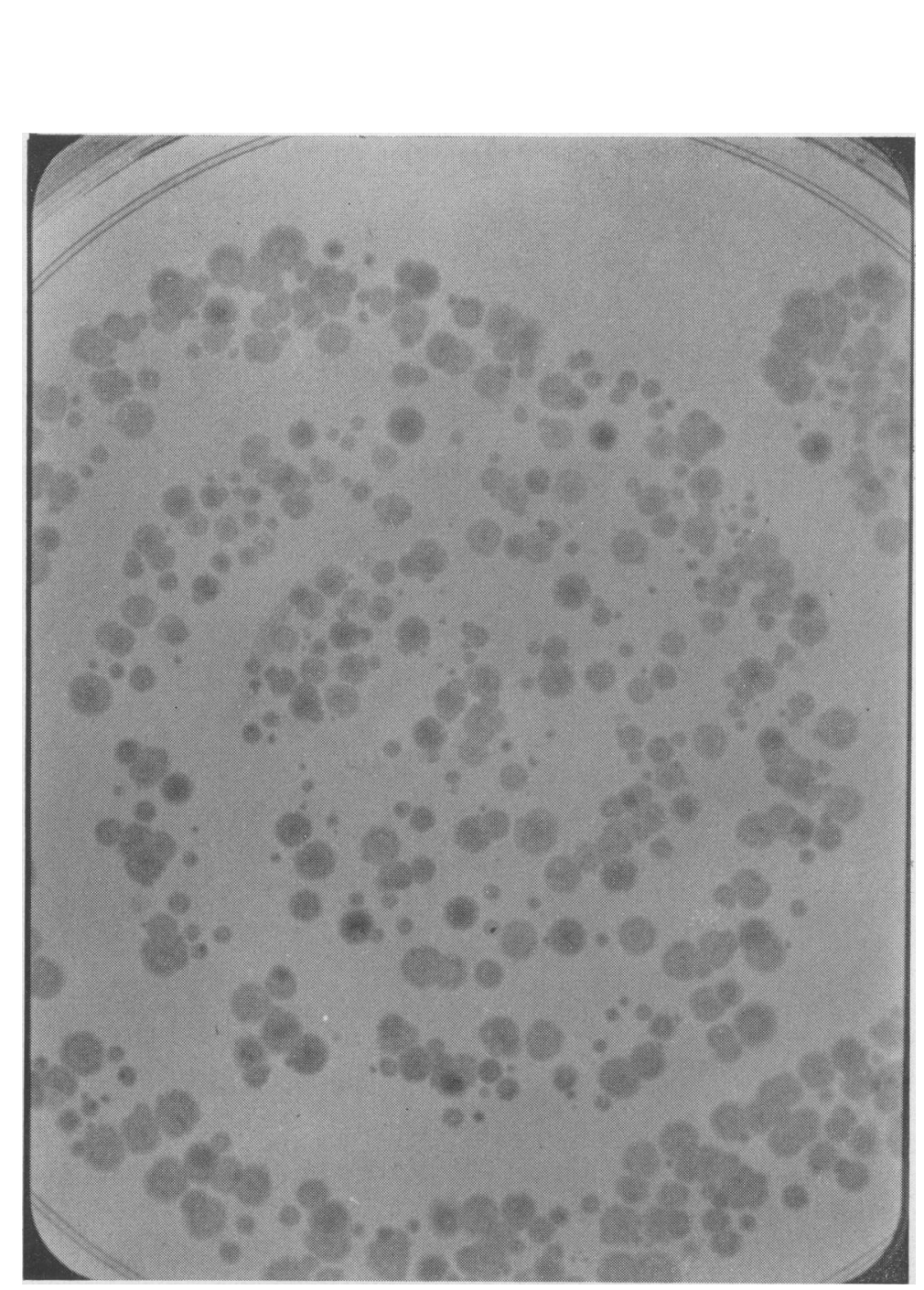

FIG. 2.-A $10-^{2}$ dilution of the same culture as in figure 1 plated on to trypticase soy agar containing $6 \mu \mathrm{g} . / \mathrm{ml}$. ampicillin. Variation in colony size and morphology is present.

\section{TABLE I}

The Relationship between Colony Count of Esch. coli on $6 \mu \mathrm{g}$. Ampicillin Agar at Varying Dilutions and the Calculated Number of Resistant Organisms in the Parent Population.

\begin{tabular}{ccc}
\hline $\begin{array}{c}\text { Log } \\
\text { Dilution }\end{array}$ & $\begin{array}{c}\text { Average No. } \\
\text { Colonies/Plate }\end{array}$ & $\begin{array}{c}\text { Apparent No. } \\
\text { Bacteria } / \mathrm{ml} .\end{array}$ \\
0 & semiconfluent & \\
1 & 368 & $1.84 \times 10^{4}$ \\
2 & 113 & $5.63 \times 10^{4}$ \\
3 & 22 & $1.07 \times 10^{5}$ \\
4 & 5 & $2.50 \times 10^{5}$
\end{tabular}

Total Count $=9.98 \times 10^{8}$ bacteria $/ \mathrm{ml}$. a more laborious serial dilution assay (Seligman and Mickey, 1964). On solid media, the problem was that for a wide range of dilutions, increase in dilution did not result in a proportionate decrease in colony count (Table I).

Saz and Eagle (1953) had found a similar phenomenon using slightly different techniques. With the current procedure, mixtures of the parent strain and approximately equal numbers of the first step mutant in broth culture did not give evidence of a "co-killing" effect.

\section{Kinetics}

Turning now to consideration of the kinetics of bactericidal activity, the question may be 


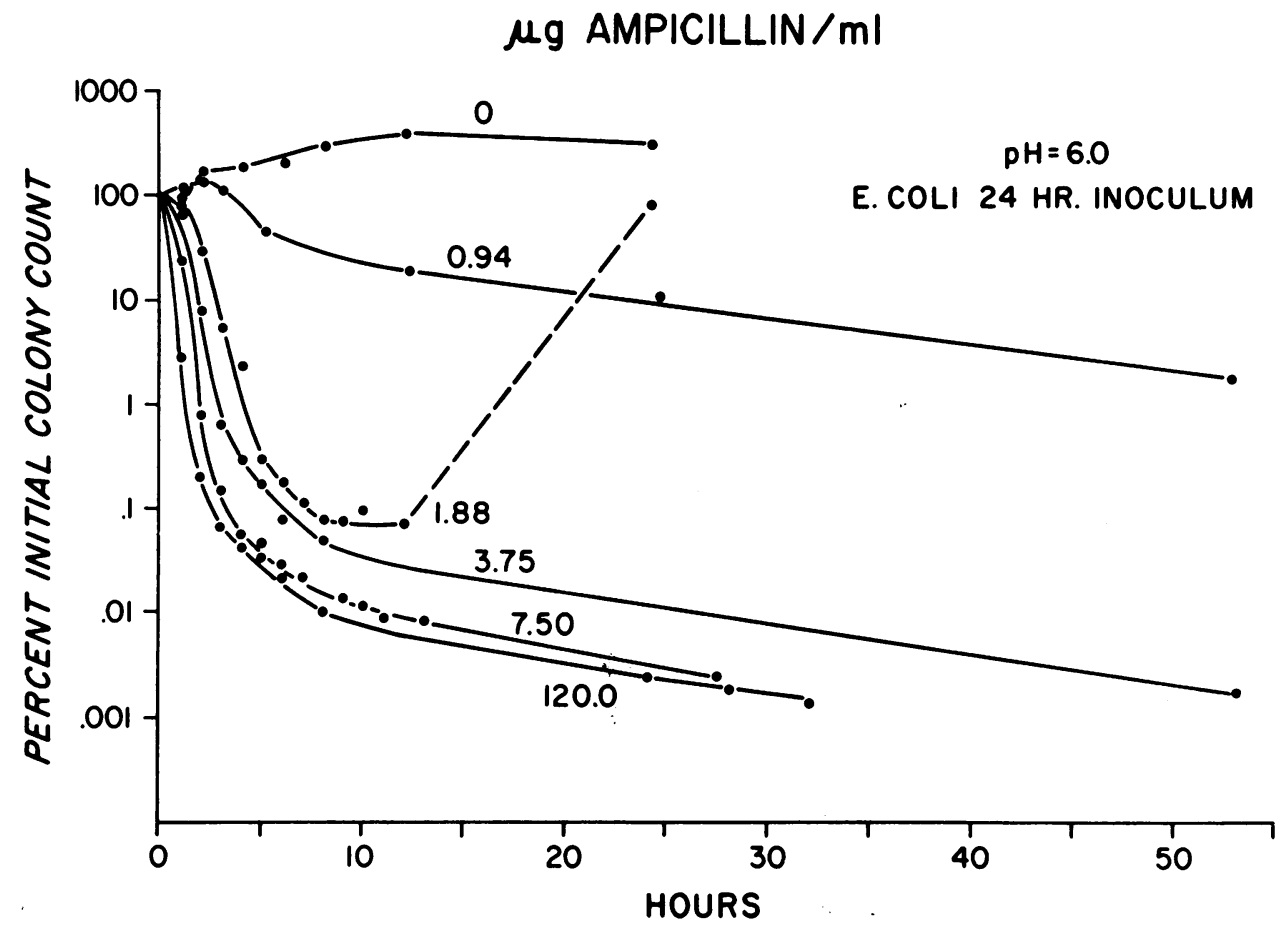

Fig. 3.-The effect of varying concentrations of ampicillin on Esch. coli. Bacterial regrowth occurred at $1.88 \mathrm{\mu g}$. ampicillin $/ \mathrm{ml}$. Initial colony count was approximately $10^{8}$ organisms $/ \mathrm{ml}$.

asked "how do the kinetics affect the apparent minimum inhibitory concentration? It turned out that several factors which had profound effect on the rate of bactericidal activity had small effect on the apparent "minimum inhibitory concentration."

The age of the inoculum, profoundly affected the rate of activity. As expected for a penicillinlike antibiotic, older cultures were less susceptible than younger ones. However, a 48-hour culture could be rejuvenated into its former susceptibility to the bactericidal activity of ampicillin after subculture for two hours in fresh media (Seligman and Hewitt, 1963). On tube dilution assay, however, a six hour and a 24 hour culture gave the same minimum inhibitory concentration, $8 \mu \mathrm{g}$. $/ \mathrm{ml}$.

The size of the inoculum did not affect the kinetics at concentrations which were sufficiently inhibitory. At borderline concentrations of ampicillin, regrowth would frequently occur (Fig. 3). With the current strain both $10^{-2}$ and $10^{-4}$ dilutions of six hour culture gave the same M.I.C. after 24 hours incubation $(8 \mu \mathrm{g}$./ $\mathrm{ml}$.).

Temperature profoundly affected reaction kinetics. At $0^{\circ} \mathrm{C}$. no bactericidal activity could be demonstrated and at room temperature the reaction rates were significantly lower than at $37^{\circ} \mathrm{C}$. a factor which illustrated the impor- $\odot$ tance of having all elements in the antibioticbacteria reaction mixture at the same temperature at the start of the experiment. With the tube dilution assay, one need not be so scrupulous. The M.I.C.s were the same, $8 \mu \mathrm{g}$. $/ \mathrm{ml}$., whether the mixtures were made at $0^{\circ} \mathrm{C}$., room 3 temperature or $37^{\circ} \mathrm{C}$. (provided, of course, that the tubes were all subsequently incubated at $37^{\circ} \mathrm{C}$.).

However, pH was an exception. Initial bactericidal activity was greater at $\mathrm{pH} 6.0$ but $ᄋ$ after two hours, greater bactericidal activity had taken place in the mixtures at pH 7.5 (Fig. 을 4). The slope of slow bactericidal activity was steeper at a more neutral $\mathrm{pH}$ than it was at $\mathrm{a}^{\circ}$ more acid one. At pH 4.9 the current strain $\tilde{O}^{\circ}$ of Esch. coli showed practically no slow bac-N tericidal activity. If bactericidal activity in the urine were of importance in treating urinaryco tract infections (and I doubt that it is) then $\bar{\varnothing}$ alkalinizing the urine might be preferable with $\stackrel{\oplus}{+}$ ampicillin treatment provided that such a $\mathrm{pH}$ 웅 


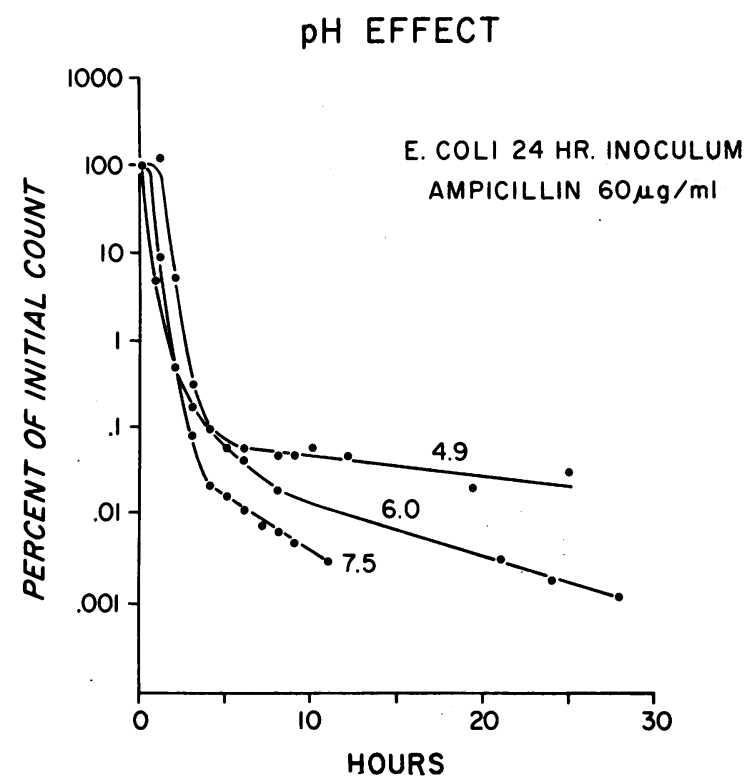

FIG. 4.-The effect of varying $\mathrm{pH}$ on the reaction curve of an ampicillin-Esch. coli mixture.

effect on slow bactericidal activity is a general phenomenen for other strains of Esch. coli and for other species.

Inspection of the M.I.C. alone, however, would lead one to suspect that $\mathrm{pH} 6.0$ is preferable to 7.3 since the M.I.C. was consistently lower at pH 6.0 (Table II). Comparison of the M.I.C. by tube dilution technique and by plate assay is included to illustrate the wide variation in apparent M.I.C. results depending upon the technique employed. It should be noted that one of the largest sources of difference depended on the dilutions used since two-fold dilutions were done for the tube dilution studies while the plates were done at closer dilutions, one half to one microgram.

\section{Conclusion}

Many factors affect the apparent in vitro activity of a compound even when one focuses attention on some simple bacterial and kinetic considerations. Mutants with increased inherent resistance and with increased penicillinase activity are present in gram-negative bac-
TABLE II

The "Minimum Inhibitory Concentration" in $\mu \mathrm{g} . / \mathrm{ml}$. Ampicillin of a Strain of Esch. coli under Varying test Conditions.

\begin{tabular}{lcc}
\hline & $\mathrm{pH} 7.3$. & $\mathrm{pH} 6.0$ \\
Tubes* & 8 & 4 \\
Plates** & $5-6$ & $1-2$ \\
\hline
\end{tabular}

*two-fold tube dilution sensitivity tests done with a 10-4 dilution of an overnight culture of $E$. coli. **approximate end point at which no growth occurred on agar plates containing varying concentrations of ampicillin which were plated with a $10^{-6}$ dilution of an overnight culture of Esch. coli.

teria. Their clinical importance is undetermined but they are possibly a frequent cause of the last positive tube on tube dilution studies to determine the "M.I.C." Consideration of reaction kinetics can lead one to suspect that such factors as a $\mathrm{pH}$ of $\mathbf{7 . 3}$ may result in greater bactericidal activity than a more acid $\mathrm{pH}$; while a tube dilution assay might lead one to suspect that greater activity was present at $\mathrm{pH}$ 6.0. It is concluded that studies involving reaction rate may be of assistance in correlating in vitro activity as measured by the traditional M.I.C. with in vivo activity. The "minimum inhibitory concentration" is not a fixed number, but a variable one which depends on the technique used to determine it.

The experiments were supported (in part) by a grant from the United States Public Health Service HD 00303 and were done during the course of a U.S.P.H.S. Research Career Development Award. Ampicillin was kindly supplied by Bristol Laboratories, Syracuse, New York.

\section{REFERENCES}

Demerec, M. (1945): Proc. Soc. Nat. Acad. Sci., 31, 16.

SAZ, A. K., and EAGLE, H. (1953): J. Bacteriol., 66, 347.

Seligman, S., and HewitT, W. L. (1963): Bacteriol., 85, 1160.

Seligman, S., and Mickey, M. R. (1964): J. Bacteriol., 88, 31. 